\title{
Effective Leadership in Higher Education: A Review of Leadership Style Preferences among Faculty and Staff within the United States
}

\author{
Joseph G. Mews \\ Palmetto College, University of South Carolina, Sumter, SC, USA \\ Email: mewsj@mailbox.sc.edu
}

How to cite this paper: Mews, J. G. (2019). Effective Leadership in Higher Education: A Review of Leadership Style Preferences among Faculty and Staff within the United States. Open Journal of Leadership, 8, 58-74. https://doi.org/10.4236/ojl.2019.82004

Received: April 22, 2019

Accepted: June 17, 2019

Published: June 20, 2019

Copyright ( 2019 by author(s) and Scientific Research Publishing Inc. This work is licensed under the Creative Commons Attribution International License (CC BY 4.0).

http://creativecommons.org/licenses/by/4.0/

\section{Open Access}

\begin{abstract}
This causal-comparative study reviewed the leadership style preferences of faculty and staff from participating higher education institutions (HEI). A total of 146 participants completed the Leadership Style Questionnaire (LSQ), a research instrument consisting of demographic questions and the Vannsimpco Leadership Survey (VLS). A single factor, one-way ANOVA (analysis of variance) was conducted, and significant differences were identified within the nine styles, $(F[8,1305]=93.65, p<0.001)$. Tukey's $H S D$ (honestly significant difference) post-hoc tests were required and revealed significant differences between 24 of the 36 leadership style pairings. The statistical analysis showed collective preferences toward Democratic-Transformational Leadership ( $M=4.25)$, Democratic Leadership $(M=4.21)$, Transformational Leadership $(M=4.21)$, and Transactional Leadership $(M=4.20)$. The least preferred style was Laissez-faire Leadership $(M=2.63)$. This study also compared leadership style preferences of participants classified as faculty versus those classified as staff. Significant differences were identified within responses for Democratic Leadership and Transactional Leadership styles.
\end{abstract}

\section{Keywords}

Leadership, Leadership Styles, Leadership Preferences, Higher Education Leadership, Organizational Leadership

\section{Introduction}

The landscape of today's higher education institutions (HEI) has changed and become increasingly multifaceted since the turn of the twenty-first-century, making it essential for colleges and universities to develop and hire savvy individuals who can effectively carry out change initiatives and lead faculty, staff, and stu- 
dents (Gigliotti \& Ruben, 2017; Wang \& Sedivy-Benton, 2016). As detailed in related literature, leaders can improve key factors such as employee job satisfaction and commitment by understanding and catering to the preferences of their followers, a viewpoint that is underrepresented in existing leadership research (Alonderiene \& Majauskaite, 2016; Lussier \& Achua, 2012; Northouse, 2015). Given the positive correlation between leader-follower relationships and organizational outcomes, there is a need for further examination surrounding the viewpoint of those being led (Hollander, 2012). This is especially true for complex organizations such as HEIs, where few leadership studies have sought feedback from participants on multiple leadership styles (Alonderiene \& Majauskaite, 2016; Eacott, 2011).

This study addressed the need for further research on the follower's perspective of leadership, specifically from employees of colleges and universities within the United States. Faculty and staff from various HEIs were surveyed to measure their preferred style of leadership utilizing the Vannsimpco Leadership Survey (VLS), a validated instrument that accounts for nine different leadership styles, including hybrids, which are detailed in Appendix C (Vann, Coleman, \& Simpson, 2014). This study is beneficial for anyone exploring preferred leadership styles of followers within organizational or higher education settings.

\subsection{Research Questions}

This study examined the following research questions:

1) What is the preferred leadership style of faculty and staff in higher education institutions?

2) Do leadership style preferences differ for employees classified as faculty versus those classified as staff?

\subsection{Assumptions}

This study was conducted with the following assumptions:

1) Participants were employed as faculty or staff at a college or university within the United States at the time of the study.

2) Faculty and staff participants had adequate involvement with supervisors to accurately portray their preferences throughout the VLS.

3) Participants responded honestly and accurately to the biographical and leadership survey questions with the understanding that data collected were confidential and anonymous.

4) One survey was submitted by each participant.

\section{Background}

Leadership studies date back to the 1940s and 1950s when The Ohio State University and the University of Michigan conducted their famous studies on behavioral theories (Northouse, 2015). Since then, a wide range of theories has been developed through studies aimed at gauging and identifying effective leadership, 
most of which have focused on the leader's perspective (Notgrass, 2014). These include recognized leader-based concepts such as the skills theory (Katz, 1955), behavioral theory (Blake \& Mouton, 1964; Fleishman, 1953), contingency theory (Fiedler, 1967), and situational theory (Hersey and Blanchard, 1969) (Notgrass, 2014). One distinguished follower-based concept, the leader-member exchange (LMX) theory, was developed in the 1970s and changed direction by focusing on the importance of positive leader-follower relationships (Gerstner \& Day, 1997). Following the LMX theory, there have been revisions to the aforementioned theories, but inadequate research has been conducted on the leadership style preferences of followers, even though evidence points to a correlation between healthy leader-follower relationships and positive organizational outcomes (Alonderiene \& Majauskaite, 2016; Northouse, 2015). In addition to limited research on the follower's perspective, existing leadership survey instruments such as the commonly-used Multifactor Leadership Questionnaire (MLQ) have limited use due to their narrow scope and lack of validity (Keshtiban, 2013; Vann, et al., 2014). This has led to the development of the VLS, a versatile and reliable leadership survey instrument (Vann, et al., 2014).

Since the turn of the twenty-first-century, it has become more apparent that effective leaders must pay close attention to the leadership style preferences of their followers, as it correlates with key factors such as employee satisfaction, retention, and commitment toward organizational objectives (Notgrass, 2014). Complex organizations such as HEIs operate under mandated policies with regular change, creating a need for perceptive leaders at every level in order to sustain continuity and sustained growth. Continued research on the perspective of followers within colleges and universities is necessary for enhanced awareness, as it not only impacts leader-follower relationships, but also student success, public perception, and financial well-being (Alonderiene \& Majauskaite, 2016; Harris, Hinds, Manansingh, Rubino, \& Morote, 2016).

\section{Methods and Procedures}

The purpose of this section is to present the methods used to identify the preferred leadership styles of faculty and staff in HEIs. The following sections detail the research paradigm and design for this study, along with the procedures for data collection and analysis.

\subsection{Research Paradigm}

While the benefits of understanding leadership style preferences of followers are evident, there has been little research conducted to identify which style is most preferred by faculty and staff in HEIs. This quantitative study aimed to address that lack of research using an online questionnaire. Titled Leadership Style Questionnaire (see Appendix A), this online instrument was created through

Google Forms, consisting of two sections: 1) Demographics, and 2) Vannsimpco Leadership Survey. The demographic section distinguished participants by gender, 
age, employment classification, and years with their current employer. The VLS section was used to identify the preferred leadership styles of all participants.

\subsection{Research Design}

Because leadership styles of faculty and staff were compared, a quantitative, causal-comparative research design was utilized for this study (Spatz, 2011). The VLS, an instrument developed by Drs. Barry Vann, Aaron Coleman, and Jennifer Simpson (2014), was selected as the ideal instrument for this study because of its validity and versatility. The VLS provides reliable feedback on nine different leadership styles based on its 27 questions (Vann et al., 2014). The leadership styles in the VLS were the dependent variables. The independent variables consisted of participant demographics, including employment classification, age, gender, and years of experience with their current employer. These independent variables were chosen to answer the research questions and provide assessment of supplemental demographic differences related to leadership style preference.

\subsection{Data Collection}

Leadership style data were collected from volunteering faculty and staff of participating institutions following approval from an author to use the VLS instrument, and approval from the Institutional Review Board (IRB) for the Protection of Human Subjects to conduct research. Prior to completing the survey, participants were provided with an email explaining the purpose of the study and a link to the questionnaire. The first page of the questionnaire provided a statement of consent confirmation of anonymity. Following the statement of consent, participants responded to four demographic questions. The final section included the 27 VLS questions. The survey was made available for four weeks, and data from all submitted questionnaires were housed in a private and secure location for analysis.

\subsection{Data Analysis}

Data were collected through Google Forms and analyzed with Microsoft Excel. Descriptive and inferential statistics were both necessary. Descriptive statistics were performed to provide analysis of the total group of participants and demographic subgroups. Inferential statistics were required to analyze the responses to the Likert-scaled VLS questions. Based on the data collected from the questionnaire, the preferred leadership styles of faculty and staff were identified using a single factor, one-way Analysis of Variance (ANOVA). Further analysis was conducted using Tukey's Honestly Significant Difference (HSD) tests to determine which leadership style pairings were significantly different (Spatz, 2011). A series of independent samples $t$-tests were conducted to detect whether the leadership style pairings were significantly different between participants classified as faculty versus those identified as staff.

\section{Findings}

This section presents the research findings from the study and provides a statis- 
tical analysis of the data collected. As outlined in the last section, a quantitative, causal-comparative research design was utilized to identify leadership style preferences among faculty and staff within higher education institutions. Participants completed the Leadership Style Questionnaire, comprised of demographic questions and the Vannsimpco Leadership Survey. To assist in answering the research questions, this section provides an analysis of the collective leadership style preferences from all participants, along with a comparative assessment between faculty and staff.

\subsection{Description of the Subjects}

The population surveyed for this study consisted of faculty and staff from various colleges and universities throughout the United States. A total of 146 participants completed and submitted the questionnaire. Of the 146 participants, 106 (72.6 percent) were classified as faculty, and 40 (27.4 percent) were classified as staff.

The demographic areas of gender, age, and experience with their current employer were also required as a part of the LSQ for added context and are detailed in Table 1. Regarding gender, 69 (47.3 percent) were female, and 77 (52.7 percent) were male. Concerning age, 10 (6.8 percent) were between the ages of 21 and 30, 32 (21.9 percent) were between the ages of 31 and 40, 37 (25.3 percent) were between the ages of 41 and 50, 26 (17.8 percent) were between the ages of 51 and 60, and 41 (28.1 percent) were age 61 or older. In terms of experience with their current employer, 60 (41.1 percent) were employed for five years or less, 21 (14.4 percent) for six to ten years, 19 (13.0 percent) for 11 to 15 years, 15 (10.3 percent) for 16 to 20 years, and 31 (21.2 percent) for 21 years or more.

Table 1. Participant demographics summary.

\begin{tabular}{cccc}
\hline Demographic Measure & Category & Number of Participants & Percentage of Participants \\
\hline \multirow{2}{*}{ Gender } & Male & 69 & $47.3 \%$ \\
& Female & 77 & $52.7 \%$ \\
& 20 or under & 0 & $0.0 \%$ \\
Age & $21-30$ & 10 & $6.8 \%$ \\
& $31-40$ & 32 & $21.9 \%$ \\
& $41-50$ & 37 & $25.3 \%$ \\
Employment & $51-60$ & 26 & $17.8 \%$ \\
Classification & 61 or over & 41 & $28.1 \%$ \\
& Faculty & 106 & $72.6 \%$ \\
& Staff & 40 & $27.4 \%$ \\
Years with & $0-5$ & 60 & $41.1 \%$ \\
current employer & $6-10$ & 21 & $14.4 \%$ \\
& $11-15$ & 19 & $13.0 \%$ \\
& $16-20$ & 15 & $10.3 \%$ \\
& 21 or more & 31 & $21.2 \%$ \\
\hline
\end{tabular}




\subsection{Research Findings}

To identify the preferred leadership style of the participants as a collective group, a single factor, one-way ANOVA test was conducted on the responses. The results from the ANOVA revealed a significant difference in leadership style preferences among the participants within the nine leadership styles. See Table 2 for details.

Tukey's $H S D$ post-hoc tests were conducted to determine which leadership style pairings were significantly different. As summarized in Appendix B, the Tukey's $H S D$ tests revealed that 24 of the 36 leadership style pairings had a significant difference. Statistical assessment revealed preferences for Democratic-Transformational Leadership $(M=4.25)$, Democratic Leadership $(M=4.21)$, Transformational Leadership $(M=4.21)$, and Transactional Leadership ( $M=$ 4.20). The least preferred style was Laissez-faire Leadership $(M=2.63)$.

A series of independent samples $t$-tests were conducted to distinguish whether leadership style preferences differed between participants classified as faculty and those classified as staff. The data were assessed for each of the nine leadership styles, and the results revealed a significant difference in preferences toward Democratic Leadership and Transactional Leadership. The other seven tests did not reveal a significant difference between faculty and staff preferences. See Table 3 for specifics.

\section{Summary}

Higher education institutions are complex and continuously-evolving organizations

Table 2. Single factor one-way ANOVA-leadership styles.

\begin{tabular}{|c|c|c|c|c|c|c|}
\hline SUMMARY & & & & & & \\
\hline Groups & Count & Sum & Mean & Variance & & \\
\hline Transactional & 146 & 613.333 & 4.20091 & 0.34403 & & \\
\hline Democratic & 146 & 614.667 & 4.21005 & 0.28508 & & \\
\hline Autocratic & 146 & 546.667 & 3.74429 & 0.41999 & & \\
\hline Autocratic-Transformational & 146 & 578.667 & 3.96347 & 0.33735 & & \\
\hline Autocratic-Transactional & 146 & 554.667 & 3.79909 & 0.48349 & & \\
\hline Democratic-Transformational & 146 & 621 & 4.25342 & 0.29932 & & \\
\hline Democratic-Transactional & 146 & 555.333 & 3.80365 & 0.46846 & & \\
\hline Transformational & 146 & 615.333 & 4.21461 & 0.36435 & & \\
\hline Laissez-faire & 146 & 383.667 & 2.62785 & 0.62454 & & \\
\hline \multicolumn{7}{|l|}{ ANOVA } \\
\hline Source of Variation & $S S$ & $d f$ & $M S$ & $F$ & $P$-value & F crit \\
\hline Between Groups & 301.897 & 8 & 37.7371 & 93.6505 & $6 \mathrm{E}-123$ & 1.94549 \\
\hline Within Groups & 525.858 & 1305 & 0.40296 & & & \\
\hline Total & 827.755 & 1313 & & & & \\
\hline
\end{tabular}


Table 3. Summary of independent samples $t$-tests for a Comparison of leadership style preferences between faculty and staff.

\begin{tabular}{ccccc}
\hline Leadership Style Tested & Faculty Mean & Staff Mean & Results & $\begin{array}{c}\text { Significant } \\
\text { Difference }\end{array}$ \\
\hline Democratic-Transformational & 4.27 & 4.20 & $(t[144]=0.72, p>0.05)$ & No \\
Transformational & 4.25 & 4.13 & $(t[144]=1.10, p>0.05)$ & No \\
Democratic & 4.30 & 3.98 & $(t[144]=3.38, p<0.01)$ & Yes \\
Transactional & 4.28 & 3.98 & $(t[144]=2.82, p<0.01)$ & Yes \\
Autocratic-Transformational & 3.96 & 3.98 & $(t[144]=0.15, p>0.05)$ & No \\
Autocratic-Transactional & 3.84 & 3.68 & $(t[144]=1.24, p>0.05)$ & No \\
Democratic-Transactional & 3.85 & 3.69 & $(t[144]=1.22, p>0.05)$ & No \\
Autocratic & 3.77 & 3.68 & $(t[144]=0.79, p>0.05)$ & No \\
Laissez-faire & 2.66 & 2.53 & $(t[144]=0.89, p>0.05)$ & No \\
\hline
\end{tabular}

that require effective leaders who understand and embrace the preferences of their followers. As detailed previously, key factors such as employee job satisfaction and commitment are impacted by the leadership approach utilized by the leader(s) of the organization (Alonderiene \& Majauskaite, 2016; Lussier \& Achua, 2012; Northouse, 2015). While a clear need for further examination into leadership style preferences from the follower's perspective was evident based on the literature review, this viewpoint had been misrepresented through existing research (Alonderiene \& Majauskaite, 2016; Eacott, 2011). This study helped address the gap in research and add value for future examination of leadership preferences within organizations and HEIs.

This study was developed to assess the two specific areas. The first was a comprehensive review of leadership style preferences among faculty and staff in HEIs as a collective group. The second was to determine whether leadership style preferences differed between participants classified as faculty and those classified as staff. This section summarizes the findings and practical significance of the study, its limitations, and implications for future research.

\subsection{Practical Significance}

To address the research questions, an electronic questionnaire was developed and distributed to faculty and staff from various colleges and universities within the United States. Titled Leadership Style Questionnaire, the research instrument consisted of demographic questions and the VLS. The LSQ was made available to the participating HEIs for four weeks, and 146 volunteering faculty and staff completed and submitted the questionnaire. Of the 146 individuals who submitted the LSQ, 106 (72.6 percent) were classified as faculty, and 40 (27.4 percent) were classified as staff.

As detailed in the previous section, findings from the statistical analysis revealed collective preferences toward Democratic-Transformational Leadership 
( $M=4.25)$, Democratic Leadership ( $M=4.21)$, Transformational Leadership ( $M$ $=4.21)$, and Transactional Leadership $(M=4.20)$. Responses for the remaining leadership styles resulted in means below 4.00, with the least preferred being Laissez-faire Leadership $(M=2.63)$. Expanding on the VLS responses, the ANOVA identified significant differences within the nine leadership styles, requiring $\mathrm{Tu}$ key's $H S D$ post-hoc tests to detect where the significant differences existed. The post-hoc tests (summarized in Appendix B) revealed significant differences in 24 of the 36 leadership style pairings.

To address the second research question, a series of independent samples $t$-tests (summarized in Table 3 ) were conducted to determine whether leadership style preferences differed between participants classified as faculty versus those classified as staff. The results revealed a significant difference in preferences toward two of the nine styles: Democratic Leadership and Transactional Leadership. Faculty participants scored Democratic Leadership $(M=4.30)$ and Transactional Leadership ( $M=4.28)$ highest of the nine styles, while staff participants scored both styles significantly lower ( $M=3.98$ for both styles). These results are worth noting, as HEI leaders with supervisory responsibilities for both faculty and staff may need to adjust their approach based on the roles of their subordinates.

Given that multiple leadership styles were preferred by the participants in this study, the findings suggest that a situational approach may be necessary to effectively lead in a college or university setting. This notion aligns with existing research on situational leadership, supporting the leader's need to dictate his or her style based on the environment and follower(s), especially in complex organizations such as HEIs (Khan, 2017). In order to utilize the situational approach effectively, the leader must get to know his or her followers, identify their needs and preferences, and adjust leadership styles as necessary (Northouse, 2015). This supports the notion that effective leaders should employ a full range of leadership behaviors based on the situation (Avolio \& Bass, 2002).

The Democratic-Transformational Leadership style can be used during times of change when involvement and inclusion are desired from followers regarding the decision-making and communication process. This style can also be adopted when mentoring opportunities are presented, both for the leader and for emerging employees (Vann et al., 2014). Since it is a hybrid leadership style, the leader may need to utilize more or less Democratic or Transformational Leadership strategies, depending on the situation.

Democratic Leadership is a collaborative style that can be effective with creative groups and select followers who are open to new ideas. This approach can also lead to the discovery of untapped potential in training or professional development settings (Bavelas \& Lewin, 1942; Rustin \& Armstrong, 2012). Based on the findings in this study, Democratic Leadership would be more appropriate with faculty than staff, since there is a significant difference in preference between the two groups of employees.

Leaders can practice Transformational Leadership when their followers begin 
to plateau or decline in performance (Lussier \& Achua, 2012). Transformational Leadership is often utilized to motivate followers and achieve at a higher rate through inspirational motivation and individualized consideration (Northouse, 2015). This is a leadership style preferred by both faculty and staff, and should be employed for relationship-building and continued progress in performance.

For followers who are relied on for repetitive or daily tasks, a Transactional Leadership approach may be best-suited (Lussier \& Achua, 2012). This leadership style is incentive-based, and ideal for roles where projects and deadlines are the priority (Hamstra, et al., 2014). This study revealed a significant difference in preferences toward Transactional Leadership, indicating a higher preference from faculty than staff. Given the contrast between employee groups, leaders in HEIs can benefit from understanding key aspects of all leadership styles and be prepared to adjust based on the situation.

\subsection{Limitations}

A few limitations were evident and should be considered when reviewing this study. The first being the delivery of the LSQ. The questionnaire was electronic and distributed via e-mail to faculty and staff from participating colleges and universities within the United States. Considering the electronic and anonymous nature of the instrument and data collection, there was opportunity for participants to respond dishonestly. There was also opportunity for recipients to respond more than once. Both of which would have skewed the results.

Secondly, the questionnaire was designed for participants to complete anonymously and independently. This method guaranteed anonymity, but also left room for misinterpretation of the questionnaire's demographic and VLS questions. Participants could have responded inaccurately if they had limited time with supervisors or misunderstood any of the questions.

Finally, the LSQ was only distributed to participating colleges and universities within the United States and was dependent on administrators for dissemination. While the response totals exceeded minimum requirements for inferential statistical analysis, the results may have differed if all colleges and universities across the country were included in the study. Also, data on distinction (e.g., research, liberal arts, etc.) and level (e.g., two-year, four-year, etc.) of the participating HEIs were not collected in this study, an aspect that could have contributed to further analysis.

\subsection{Implications of the Findings}

Considering the limited amount of research that currently exists on leadership style preferences from the follower's perspective, there is great opportunity for continued examination of this viewpoint. This is especially true given the evidence that supports the concept of leaders embracing followers and building healthy relationships. As detailed previously, leaders who invest time and energy in getting to know their followers have greater success when implementing 
change initiatives and building trust within their organization. The same is true for colleges and universities, where complex landscapes often create challenging situations that require support and commitment from followers and stakeholders.

Future research could expand on this study by including larger groups of participants from more HEIs across the United States, and even internationally. Larger sample sizes could aid existing research and provide further insight into the preferences of followers from colleges and universities, and organizations in general. Another opportunity is inclusion of additional demographic questions. Including supplementary questions related to employee job satisfaction and commitment could provide supporting evidence to correlate with leadership style preferences. Collecting data on organizational specifics (e.g., location, team size, sector, etc.), could also add valuable context for future studies.

\subsection{Closing}

This study addressed a gap in research by assessing leadership style preferences among faculty and staff in higher education institutions. The findings showed an overall preference toward Democratic-Transformational Leadership $(M=4.25)$, with additional support for Democratic Leadership $(M=4.21)$, Transformational Leadership $(M=4.21)$, and Transactional Leadership $(M=4.20)$. The least preferred style was Laissez-faire Leadership $(M=2.63)$. A single factor, one-way ANOVA found significant differences within the nine leadership styles. Tukey's $H S D$ post-hoc tests revealed significant differences between 24 of the 36 leadership style pairings.

Significant differences in leadership style preferences were identified between participants classified as faculty and those classified as staff. Independent samples $t$-tests revealed significant differences in preference toward Democratic Leadership and Transactional Leadership. Faculty participants preferred Democratic Leadership $(M=4.30)$ and Transactional Leadership $(M=4.28)$ at a significantly higher level than staff participants ( $M=3.98$ for both styles).

The conclusions provide a sense of which leadership styles are preferred, while also acknowledging that followers may prefer a different leadership approach than others based on their role. These findings can be used to provide awareness for current and future leaders within complex organizations such as HEIs. The results can also aid future studies involving organizational and higher education leadership as the underrepresented viewpoint of the follower continues to be examined.

\section{Conflicts of Interest}

The author declares no conflicts of interest regarding the publication of this paper.

\section{References}

Alonderiene, R., \& Majauskaite, M. (2016). Leadership Style and Job Satisfaction in 
Higher Education Institutions. International Journal of Educational Management, 30, 140-164. https://doi.org/10.1108/IJEM-08-2014-0106

Avolio, B. J., \& Bass, B. M. (2002). Developing Potential across a Full Range of Leadership TM: Cases on Transactional and Transformational Leadership. Mahwah, NJ: Psychology Press.

Bass, B. M. (1990). From Transactional to Transformational Leadership: Learning to Share the Vision. Organizational Dynamics, 18, 19-31. https://doi.org/10.1016/0090-2616(90)90061-S

Bass, B. M., \& Stogdill, R. M. (1990). Bass \& Stogdill's Handbook of Leadership: Theory, Research, and Managerial Applications (3rd ed.). New York: Free Press.

Bavelas, A., \& Lewin, K. (1942). Training in Democratic Leadership. The Journal of Abnormal and Social Psychology, 37, 115. https://doi.org/10.1037/h0060358

Carew, D. K., Parisi-Carew, E., \& Blanchard, K. H. (1986). Group Development and Situational Leadership: A Model for Managing Groups. Training \& Development Journal, 40, 46-50.

Deluga, R. J. (1990). The Effects of Transformational, Transactional, and Laissez Faire Leadership Characteristics on Subordinate Influencing Behavior. Basic and Applied Social Psychology, 11, 191-203. https://doi.org/10.1207/s15324834basp1102 6

Eacott, S. (2011). New Look Leaders or a New Look at Leadership? International Journal of Educational Management, 25, 134-143. https://doi.org/10.1108/09513541111107560

Gastil, J. (1994). A Definition and Illustration of Democratic Leadership. Human Relations, 47, 953. https://doi.org/10.1177/001872679404700805

Gerstner, C. R., \& Day, D. V. (1997). Meta-Analytic Review of Leader-Member Exchange Theory: Correlates and Construct Issues. Journal of Applied Psychology, 82, 827-844. https://doi.org/10.1037/0021-9010.82.6.827

Gigliotti, R. A., \& Ruben, B. D. (2017). Preparing Higher Education Leaders: A Conceptual, Strategic, and Operational Approach. Journal of Leadership Education, 16, 96-114. https://doi.org/10.12806/V16/I1/T1

Hamstra, M. R. W., Van Yperen, N. W., Wisse, B., \& Sassenberg, K. (2014). Transformational and Transactional Leadership and Followers' Achievement Goals. Journal of Business and Psychology, 29, 413-425. https://doi.org/10.1007/s10869-013-9322-9

Harris, K., Hinds, L., Manansingh, S., Rubino, M., \& Morote, E. S. (2016). What Type of Leadership in Higher Education Promotes Job Satisfaction and Increases Retention? Journal for Leadership and Instruction, 15, 27-32.

Hollander, E. (2012). Inclusive Leadership: The Essential Leader-Follower Relationship. Abingdon-on-Thames: Routledge. https://doi.org/10.4324/9780203809914

Keshtiban, A. E. (2013). The Challenges and Benefits of the Multi-Factor Leadership Questionnaire (MLQ), in Terms of Gender and the Level of Analysis: A Critical Review of Current Research. In Proceedings of the European Conference on Management, Leadership \& Governance (pp. 58-65). Cambridge, MA.

Khan, N. (2017). Adaptive or Transactional Leadership in Current Higher Education: A Brief Comparison. The International Review of Research in Open and Distributed Learning, 18, 178-183. https://doi.org/10.19173/irrodl.v18i3.3294

http://www.irrodl.org/index.php/irrodl/article/view/3294

Lussier, R. N., \&Achua, C. F. (2012). Leadership: Theory, Application, and Skill Development (5th ed.). Boston, MA: Cengage Learning.

Northouse, P. G. (2015). Leadership: Theory and Practice (7th ed.). Thousand Oaks, CA: 
SAGE.

Notgrass, D. (2014). The Relationship between Followers' Perceived Quality of Relationship and Preferred Leadership Style. Leadership \& Organization Development Journal, 35, 605-621. https://doi.org/10.1108/LODJ-08-2012-0096

Rustin, M., \& Armstrong, D. (2012). What Happened to Democratic Leadership? Soundings, 50, 59-71. https://doi.org/10.3898/136266212800379482

Spatz, C. (2011). Basic Statistics: Tales of Distributions (10th ed.). New York: Wadsworth.

Vann, B. A., Coleman, A. N., \& Simpson, J. A. (2014). Development of the Vannsimpco Leadership Survey: A Delineation of Hybrid Leadership Styles. Swiss Business School Journal of Applied Business Research, 3, 28-38.

Wang, V. C., \& Sedivy-Benton, A. L. (2016). Leadership Misplacement: How Can This Affect Institutions of Higher Education? New Horizons in Adult Education and Human Resource Development, 28, 14-25. https://doi.org/10.1002/nha3.20148 


\section{Appendix A}

\section{Leadership Style Questionnaire \\ Part 1: Demographics}

Select the response that best describes you for each of the following:

1) Gender

$\square$ Male

$\square$ Female

2) Age

$\square 20$ or under

$\square 21-30$

$\square 31-40$

$\square 41-50$

$\square 51-60$

$\square 61$ or over

3) Employment classification

$\square$ Faculty

$\square$ Staff

4. Years with current employer

$\square 0$ - 5

$\square 6-10$

$\square 11-15$

$\square 16-20$

$\square 21$ or more

Part 2: Vannsimpco Leadership Survey

Select the response that most accurately represents your feeling on the following statements:

1 Supervisors should make it a point to reward staff for achieving organizational goals.

Strongly Disagree 1 Disagree 2 Neutral 3 Agree 4 Strongly Agree 5

2 Supervisors should let staff members know what to expect as rewards for achieving goals.

Strongly Disagree 1 Disagree 2 Neutral 3 Agree 4 Strongly Agree 5 3 Supervisors should set deadlines and clearly state the positive or negative consequences of staff members' not meeting defined goals.

Strongly Disagree 1 Disagree 2 Neutral 3 Agree 4 Strongly Agree 5 4 Supervisors should give staff authority to make important decisions.

Strongly Disagree 1 Disagree 2 Neutral 3 Agree 4 Strongly Agree 5 5 Supervisors should seek input from staff when formulating policies and procedures for implementing them.

Strongly Disagree 1 Disagree 2 Neutral 3 Agree 4 Strongly Agree 5 6 To solve problems, supervisors should have meetings with staff members before correcting issues.

Strongly Disagree 1 Disagree 2 Neutral 3 Agree 4 Strongly Agree 5 
7 It is the supervisor's ultimate responsibility for whether the organization achieves its goals.

Strongly Disagree 1 Disagree 2 Neutral 3 Agree 4 Strongly Agree 5

8 Supervisors should make quick decisions in times of urgency and be more deliberate in making decisions during times of less urgency.

Strongly Disagree 1 Disagree 2 Neutral 3 Agree 4 Strongly Agree 5

9 Supervisors should assign specific tasks to key staff members in order to achieve specific goals.

Strongly Disagree 1 Disagree 2 Neutral 3 Agree 4 Strongly Agree 5

10 Supervisors should provide the goal for the organization and allow staff to work towards achieving the goal, making sure to offer them feedback concerning their efforts.

Strongly Disagree 1 Disagree 2 Neutral 3 Agree 4 Strongly Agree 5

11 Supervisors should retain control of decision making, but they should encourage high morale so followers can more effectively implement change.

Strongly Disagree 1 Disagree 2 Neutral 3 Agree 4 Strongly Agree 5

12 Supervisors are responsible for the operation of the organization or department, which includes the development of the competencies and commitment of personnel.

Strongly Disagree 1 Disagree 2 Neutral 3 Agree 4 Strongly Agree 5

13 In addition to having responsibility for decision-making, it is essential for a supervisor to provide incentives and disincentives for staff with respect to work they have done on assigned projects.

Strongly Disagree 1 Disagree 2 Neutral 3 Agree 4 Strongly Agree 5

14 Supervisors should state clearly the incentives and disincentives to followers while maximizing oversight on the most critical decisions.

Strongly Disagree 1 Disagree 2 Neutral 3 Agree 4 Strongly Agree 5

15 Supervisors make the key decisions for the organization and get most of the credit or blame, but they should make sure that their promises for rewards and disincentives made to workers are kept.

Strongly Disagree 1 Disagree 2 Neutral 3 Agree 4 Strongly Agree 5

16 Supervisors should provide opportunities for staff members to be involved in decision making while serving as mentors during times of change.

Strongly Disagree 1 Disagree 2 Neutral 3 Agree 4 Strongly Agree 5

17 Supervisors should be open to others' ideas, yet he or she should guide employees to become stronger workers.

Strongly Disagree 1 Disagree 2 Neutral 3 Agree 4 Strongly Agree 5

18 Supervisors should be highly concerned about developing staff's ability to contribute to making important organizational decisions.

Strongly Disagree 1 Disagree 2 Neutral 3 Agree 4 Strongly Agree 5

19 Supervisors should be comfortable working with groups to seek their input in making decisions while providing incentives and disincentives for the quality of their work. 
Strongly Disagree 1 Disagree 2 Neutral 3 Agree 4 Strongly Agree 5

20 In order to make decisions, supervisors should discuss issues with all of the staff members while considering which incentives and disincentives should be used in response to the quality of their work.

Strongly Disagree 1 Disagree 2 Neutral 3 Agree 4 Strongly Agree 5

21 Supervisors should be concerned about building consensus among staff members while making sure they understand the timelines, as well as their benefits and penalties in relation to achieving goals.

Strongly Disagree 1 Disagree 2 Neutral 3 Agree 4 Strongly Agree 5

22 Supervisors should rely on personal influence and relationship building rather than on position or title to get staff to do work tasks.

Strongly Disagree 1 Disagree 2 Neutral 3 Agree 4 Strongly Agree 5

23 Supervisors should develop strategies to develop the staff's competence and commitment.

Strongly Disagree 1 Disagree 2 Neutral 3 Agree 4 Strongly Agree 5

24 Supervisors should look for ways to develop the strengths of staff members.

Strongly Disagree 1 Disagree 2 Neutral 3 Agree 4 Strongly Agree 5

25 Supervisors' jobs are to read reports and "see the big picture;" nearly all of their work should involve little or no direction of the staff members who make point of contact decisions.

Strongly Disagree 1 Disagree 2 Neutral 3 Agree 4 Strongly Agree 5

26 Staff members should be hired with skills necessary to make decisions in the workplace. If staff members need direct supervision, they should not be working in the organization.

Strongly Disagree 1 Disagree 2 Neutral 3 Agree 4 Strongly Agree 5

27 Supervisors should hire competent and committed staff members, which relieves the "manager" from making most of the day-to-day decisions.

Strongly Disagree 1 Disagree 2 Neutral 3 Agree 4 Strongly Agree 5

\section{Appendix B}

Summary of Tukey's HSD Post-Hoc Tests for a Comparison of Means among Leadership Styles

\begin{tabular}{clccc}
\hline Test & \multicolumn{1}{c}{ Leadership Styles } & Means & Results & Significant \\
\hline 1 & Transactional and Democratic & 4.20 and 4.21 & $(H S D[1305]=0.17, p>0.05)$ & No \\
2 & Transactional and Autocratic & 4.20 and 3.74 & $(H S D[1305]=8.69, p<0.01)$ & Yes \\
3 & Transactional and Autocratic-Transformational & 4.20 and 3.96 & $(H S D[1305]=4.52, p<0.05)$ & Yes \\
4 & Transactional and Autocratic-Transactional & 4.20 and 3.80 & $(H S D[1305]=7.65, p<0.01)$ & Yes \\
5 & Transactional and Democratic-Transformational & 4.20 and 4.25 & $(H S D[1305]=1.00, p>0.05)$ & No \\
6 & Transactional and Democratic-Transactional & 4.20 and 3.80 & $(H S D[1305]=7.56, p<0.01)$ & Yes \\
7 & Transactional and Transformational & 4.20 and 4.21 & $(H S D[1305]=0.26, p>0.05)$ & No \\
\hline
\end{tabular}




\section{Continued}

\begin{tabular}{|c|c|c|c|c|}
\hline 8 & Transactional and Laissez-faire & 4.20 and 2.63 & $(H S D[1305]=29.94, p<0.01)$ & Yes \\
\hline 9 & Democratic and Autocratic & 4.21 and 3.74 & $(H S D[1305]=8.87, p<0.01)$ & Yes \\
\hline 10 & Democratic and Autocratic-Transformational & 4.21 and 3.96 & $(H S D[1305]=4.69, p<0.05)$ & Yes \\
\hline 11 & Democratic and Autocratic-Transactional & 4.21 and 3.80 & $(H S D[1305]=7.82, p<0.01)$ & Yes \\
\hline 12 & Democratic and Democratic-Transformational & 4.21 and 4.25 & $(H S D[1305]=0.83, p>0.05)$ & No \\
\hline 13 & Democratic and Democratic-Transactional & 4.21 and 3.80 & $(H S D[1305]=7.74, p<0.01)$ & Yes \\
\hline 14 & Democratic and Transformational & 4.21 and 4.21 & $(H S D[1305]=0.09, p>0.05)$ & No \\
\hline 15 & Democratic and Laissez-faire & 4.21 and 2.63 & $(H S D[1305]=30.12, p<0.01)$ & Yes \\
\hline 16 & Autocratic and Autocratic-Transformational & 3.74 and 3.96 & $(H S D[1305]=4.17, p>0.05)$ & No \\
\hline 17 & Autocratic and Autocratic-Transactional & 3.74 and 3.80 & $(H S D[1305]=1.04, p>0.05)$ & No \\
\hline 18 & Autocratic and Democratic-Transformational & 3.74 and 4.25 & $(H S D[1305]=9.69, p<0.01)$ & Yes \\
\hline 19 & Autocratic and Democratic-Transactional & 3.74 and 3.80 & $(H S D[1305]=1.13, p>0.05)$ & No \\
\hline 20 & Autocratic and Transformational & 3.74 and 4.21 & $(H S D[1305]=8.95, p<0.01)$ & Yes \\
\hline 21 & Autocratic and Laissez-faire & 3.74 and 2.63 & $(H S D[1305]=21.25, p<0.01)$ & Yes \\
\hline 22 & Autocratic-Transformational and Autocratic-Transactional & 3.96 and 3.80 & $(H S D[1305]=3.13, p>0.05)$ & No \\
\hline 23 & Autocratic-Transformational and Democratic-Transformational & 3.96 and 4.25 & $(H S D[1305]=5.52, p<0.01)$ & Yes \\
\hline 24 & Autocratic-Transformational and Democratic-Transactional & 3.96 and 3.80 & $(H S D[1305]=3.04, p>0.05)$ & No \\
\hline 25 & Autocratic-Transformational and Transformational & 3.96 and 4.21 & $(H S D[1305]=4.78, p<0.05)$ & Yes \\
\hline 26 & Autocratic-Transformational and Laissez-faire & 3.96 and 2.63 & $(H S D[1305]=25.42, p<0.01)$ & Yes \\
\hline 27 & Autocratic-Transactional and Democratic-Transformational & 3.80 and 4.25 & $(H S D[1305]=8.65, p<0.01)$ & Yes \\
\hline 28 & Autocratic-Transactional and Democratic-Transactional & 3.80 and 3.80 & $(H S D[1305]=0.09, p>0.05)$ & No \\
\hline 29 & Autocratic-Transactional and Transformational & 3.80 and 4.21 & $(H S D[1305]=7.91, p<0.01)$ & Yes \\
\hline 30 & Autocratic-Transactional and Laissez-faire & 3.80 and 2.63 & $(H S D[1305]=22.29, p<0.01)$ & Yes \\
\hline 31 & Democratic-Transformational and Democratic-Transactional & 4.25 and 3.80 & $(H S D[1305]=8.56, p<0.01)$ & Yes \\
\hline 32 & Democratic-Transformational and Transformational & 4.25 and 4.21 & $(H S D[1305]=0.74, p>0.05)$ & No \\
\hline 33 & Democratic-Transformational and Laissez-faire & 4.25 and 2.63 & $(H S D[1305]=30.94, p<0.01)$ & Yes \\
\hline 34 & Democratic-Transactional and Transformational & 3.80 and 4.21 & $(H S D[1305]=7.82, p<0.01)$ & Yes \\
\hline 35 & Democratic-Transactional and Laissez-faire & 3.80 and 2.63 & $(H S D[1305]=22.38, p<0.01)$ & Yes \\
\hline 36 & Transformational and Laissez-faire & 4.21 and 2.63 & $(H S D[1305]=30.20, p<0.01)$ & Yes \\
\hline
\end{tabular}

\section{Appendix C}

\section{Definitions}

The following terms and definitions were used in this study:

Autocratic Leadership: A leadership style that limits subordinates' input, centered around the leader making all decisions for themselves and the followers (Bass \& Stogdill, 1990).

Autocratic-Transactional Leadership: A hybrid leadership style where the leader is responsible for key decisions and provides clear incentives or disincentives for followers based on assigned projects (Vann et al., 2014). 
Autocratic-Transformational Leadership: A hybrid leadership style where the leader assumes control of the decision-making process while using encouraging feedback to achieve change initiatives and objectives (Vann et al., 2014).

Democratic Leadership: A leadership style focused on deliberation and inclusion, where the leader distributes responsibility, encourages participation, engages followers, and caters to their ideas (Gastil, 1994).

Democratic-Transactional Leadership: A hybrid leadership style where the leader consults with followers throughout the decision-making process while outlining clear incentives and disincentives for assigned tasks and projects (Vann et al., 2014).

Democratic-Transformational Leadership: A hybrid leadership style where the leader involves followers in the decision-making process and provides guidance as a mentor during times of change (Vann et al., 2014).

Higher Education Institution (HEI): A postsecondary organization, most commonly referring to a two- or four-year college or university (Alonderiene \& Majauskaite, 2016).

Laissez-faire Leadership: A passive approach to leadership, where the leader is "reluctant to influence subordinates or give direction" (Deluga, 1990: p. 192).

Situational Leadership: A leadership approach where the leader adopts a style from various combinations of directive and supportive behaviors based on the situation and group (Carew, Parisi-Carew, \& Blanchard, 1986).

Transactional Leadership: A leadership style based on transactions between the leader and follower, providing incentives and disincentives for expected performance (Bass, 1990).

Transformational Leadership: A leadership style where the leader continuously challenges the status quo and achieves new heights with personal charisma, inspiration, intellectual stimulation, and individualized consideration (Bass, 1990). 